\title{
WHAT DRIVES LIQUIDITY OF TOURISM COMPANIES? MICROECONOMIC EVIDENCE FROM BULGARIA, CZECH REPUBLIC AND POLAND
}

\author{
Tomáš Heryán ${ }^{1}$ \\ ${ }^{1}$ Department of Finance and Accounting, School of Business Administration in Karviná, Silesian University in \\ Opava, Univerzitní nám. 1934/3, 73340 Karviná, Czech Republic
}

To cite this article: HERYÁN TOMÁŠ. 2018. What Drives Liquidity of Tourism Companies? Microeconomic Evidence from Bulgaria, Czech Republic and Poland. Acta Universitatis Agriculturae et Silviculturae Mendelianae Brunensis, 66(6): 1477-1484.

To link to this article: https://doi.org/10.11118/actaun201866061477

\begin{abstract}
Current paper focuses on business economics of tourism industry. Liquidity of a company has the key role within financial management among all industries, including the tourism as well. However, the question still remains: What drives the liquidity among hotels and travel agencies? The aim of the paper is to investigate whether or not is the liquidity among tourism companies in Bulgaria, Czech Republic and Poland affected by other selected microeconomic variables. It is obtained financial data from annual reports of 1,892 tourism companies collected within Amadeus, the international statistical database. Estimated period is from 2006 till 2015. In particular it has been explored three variables (i) return on assets, (ii) share of stockholders' funds, and (iii) average length of loans from creditors. As the main estimation method is employed the Generalized Method of Moments (GMM) with panel data. A comparison is made between both, large as well as medium sized hotels and travel agencies in selected countries. Except of a few, it was proven that reinvestments of the decreasing profit supported liquidity among tourism companies during a period affected by the global financial crisis.
\end{abstract}

Keywords: hotels and travel agencies, cash conversion cycle, panel GMM model

\section{INTRODUCTION}

Working capital ratios are useful tools in appraising the financial strength and immediate solvency of a company. The financial analyst must rely on these ratios. From an operational point of view, however, the money manager's primary concern is with the current cash flows and those flows expected in the near future. He can take little comfort in a satisfactory working capital ratio when he does not have funds to meet an immediately due payment. (Sagan, 1955, p. 128)

Even though according Creditreform (2017) the total number of corporate insolvencies in the states of Central and Eastern Europe in 2016 climbed slightly, it is still important to pay attention to the financial development among companies before 2016, during a period affected by the impact of the global financial crisis. Creditreform (2017) argued, this climbing was caused particularly by cases in Poland (minus $22.5 \%$ ) and Romania (minus 21.6\%), Bulgaria (minus 19.6\%) and the Czech Republic (minus 18.8\%). According to Creditreform (2017) Bulgaria's economy has developed surprisingly well. In 2016, gross domestic product grew by over three percent, fueled especially by private consumption. There has been a further fall in the unemployment rate. After 
peaking in 2012, with nearly 8,400 applications for insolvency, the situation has eased appreciably also in the Czech Republic. One factor in this has been the good economic development. However, the pace of GDP growth has slipped from 4.5 percent in 2015 to around 2.5 percent, following a pause in the investment activity dependent on EU funds. Further, with economic growth of more than three percent in 2016, Poland is one of the EU countries exhibiting a dynamic upturn. Thanks to higher real-term incomes, private consumption in particular expanded robustly. Investment, on the other hand, remained weak.

Insolvency of a company is directly connected to its profitability, liquidity, or even working capital. Although working capital management is vital because of its impact on the firm's profitability and risk, and consequently its value, it has received less attention than to capital budgeting, capital structure, or dividend policy among the literature (Chang, 2018). Current paper therefore focuses on working capital management. Main contribution of this paper is within the first investigation of this microeconomic issue among companies of tourism ever. The aim of this study is to investigate whether or not is the liquidity among tourism companies in Bulgaria, Czech Republic and Poland affected by other selected microeconomic variables. The estimation period is from 2006 till 2015, so we can see the relations during the period affected by the global financial crisis.

The paper is structured as follows. Next section briefly reviews recent literature, Section 3 describes data and methodology, next section brings the discussion on the empirical results and Section 5 concludes the paper.

\section{Literature review}

Working capital management is key to the operational performance of the company, as well as its value. The overwhelming majority of current corporate finance literature focuses on business performance and long-term financing issues, including decision-making on the change in capital structure in terms of capital costs. However, the problem of liquidity management in relation to business performance is much less investigated. (Chang, 2018)

Chang (2018) examines the Cash Conversion Cycle (CCC) and its impact on global performance. There is a statistically significant negative relationship between the CCC and the return on assets of the total invested capital. This finding indicates that companies are trying to maximize CCC cuts to boost their performance. However, this relationship is much weaker or even the opposite, so positive for companies with lower CCC values. The author's study contributes to the efficient operation of financial management, and because of international comparisons, the results of the assistance can determine the allocation of current assets to their total capital.
The same conclusion is reached by Zeidan and Shapir (2017). They are, however, facing two barriers to investigating the above relationship. First, there is no theoretical model describing investments in net working capital. There are also differences in the decisions that managers make, compared to what managers should do. In particular, the fact that the existence of net working capital means lower risk is also highlighted, and they are also associated with lower returns than is the case for investment assets. Endogeneity is also taken into an account with by Chang (2018). Just as the claim that lower working capital is associated with higher profits, the claim that higher profits are associated with a lower rate of net working capital, and vice versa.

Zeidan and Shapir (2017) further argue that if instant liquidity and working capital become substitutes that compete against financial investment because of the lack of capital, SMEs in emerging markets faced with credit constraints should pay particular attention to increased attention to CCC management within their sustainability or growth strategies. In addition, Luo (2011), in the case of SMEs and their lack of capital, adds that the problem motivates managers to save more cash for more attractive projects in the future than they would currently invest in projects with negative net present value.

Smaller companies are very often confronted with the problem of capital constraints and are therefore forced to secure sufficient liquidity. Following the CCC minimization, it is necessary to try to negotiate the minimum maturity of the obligations always longer than the CCC length. The opposite case, i.e. The shorter maturity of the obligations, always increases additional costs. (Moussawi-Haidar and Jaber, 2013)

When it comes to liquidity and its indicators, there is no doubt the advantage of their easy calculation and instantaneous value. However, a significant disadvantage against to the CCC is an ability to provide information at a single time when we cannot be sure of the day before the balance sheet was drawn up. Moreover, when managing working capital is efficiently, the need for additional foreign financing is reduced, which reduces interest costs, increases performance and indirectly increases even market value companies. (Cagle, CGMA and Campbell, 1980)

\section{MATERIALS AND METHODS}

This section is divided into three sub-sections, data used in current paper, methodology as well as theoretical assumptions of the main model.

\section{Data}

It has been obtained annual data for 1,892 tourism companies from Amadeus, the international statistical database. Estimated period is from 2006 till 2015. Particular numbers of large as well as medium sized hotels and travel agencies from 
I: Amounts of the tourism companies in selected countries

\begin{tabular}{lccccc}
\hline & \multicolumn{3}{c}{ HOTELS } & \multicolumn{2}{c}{ AGENCIES } \\
\cline { 2 - 6 } & large & medium & 581 & large & medium \\
\hline Bulgaria & 52 & 421 & 20 & 108 \\
Czechia & 56 & 312 & 14 & 158 & 110 \\
Poland & 54 & & & 6 & 14 \\
\hline
\end{tabular}

Source: Author's calculation.

Bulgaria, Czechia and Poland are included in Tab. I. For other two countries of Visegrad group, Slovakia and Hungary, there were estimated only statistical non-significant relations. Both countries have been excluded from the investigation. In particular, it has been collected amounts for the companies' earnings before interests and taxes (EBIT), turnover (both from their profit and loss statements), assets in total, current assets, inventories, short-term receivables, stockholders' funds, current liabilities, short-term payables (all from their balance sheets). According to data it is able to explore a few selected ratios, finally used in the equation (6).

\section{Methodology}

The inventory turnover ratio represents the relationship between the cost of merchandise inventory sold and the ending inventory for the period. The inventory turnover ratio measures how efficiently the overall inventory is sold. (Sherman, 2015, p. 61) The Days Purchases in Inventory is explored as in Zeidan and Shapir (2017) through the first equation (1):

$$
D P I_{i t}=\frac{365}{O T_{i t} / I N_{i t}}
$$

where $D P I_{i t}$ is days purchases in inventory of $i$ companies in time $t, O T_{i t}$ means operating turnover and the variable $I N_{i t}$ is inventory or stock in the company.

According to Sherman (2015, p. 56) the average collection period (also known as days sales outstanding) measures the time it takes to collect cash from customers once the sales have been made. Many analysts calculate the average collection period by first finding the average credit sales per day and then dividing the average accounts receivable by the average credit sales per day. The Average Collection Period in days is examined according to Zeidan and Shapir (2017) through the equation (2):

$$
A C P_{i t}=\frac{365}{O T_{i t} / D R_{i t}},
$$

where $A C P_{i t}$ means the average collection period of $i$ companies in time $t, O T_{i t}$ is operating turnover and $D R_{i t}$ means debtors' receivables.

Days purchases in payables, or the Average Purchase's Period is then explained simultaneously as in Zeidan and Shapir (2017) through the equation (3) as:

$$
A P P_{i t}=\frac{365}{O T_{i t} / C P_{i t}}
$$

where $A P P_{i t}$ is the average purchase's period of $i$ companies in time $t, \mathrm{OT}_{i t}$ means operating turnover and $C P_{i t}$ is creditors' payables.

The operating cycle recognizes the total elapsed time from the ordering of raw materials through the receipt and availability of customer payments. As this time period increases, there are more opportunities for delays in processing or cash receipts to drain financial resources. However, at least partially offsetting the limitations in available cash are the payment policies of the company. Together, these measures create the cash conversion cycle, the amount of time from the outflow of cash until it is recovered. (Sherman, 2015, p. 61) The Cash Conversion Cycle is calculated according to Zeidan and Shapir (2017) as well as Sherman (2015) within next equation (4):

$C C C_{i t}=D P I_{i t}+A C P_{i t}-A P P_{i t}$,

where $\mathrm{CCC}_{i t}$ stands for the cash conversion cycle, $D P I_{i t}$ means days purchases in inventory calculated through the equation (1), $A C P_{i t}$ the average collection period for debtors' receivables according to the equation (2), and $A P P_{i t}$ means the average purchase's period for creditors' payables according to (3).

On the other hand, which is more valuable for us, it is possible to examine the period of the creditors' loan $P C L_{i t}$ analogically from equation (4) using the next equation (5):

$P C L_{i t}=A P P_{i t}-A C P_{i t}$

The main estimation is Generalized Method of Moments (GMM). In particular it has been used two-step model using the orthogonal deviations through the with panel data of those large as well as medium sized hotels and travel agencies. To reach the aim of the paper it is employed model based on Heryán and Tzeremes (2017) according to next equation (6):

$$
\begin{aligned}
& L 2_{i t}=\beta_{0} L 2_{i(t-1)} \alpha_{i t}+\beta_{1} R O A_{i t}+\beta_{2} R O A_{i(t-1)}+ \\
& +\beta_{3} \operatorname{SFR}_{i t}+\beta_{4} S_{F} R_{i(t-1)}+\beta_{5} P C L_{i t}+\beta_{6} P C L_{i(t-1)}+\varepsilon
\end{aligned}
$$

where $L 2_{i t}$ means the quick test for liquidity when inventories of $i$ companies at time $t$ are excluded from a share of current assets on current liabilities, 
$R O A_{\text {it }}$ is return on assets calculated as the EBIT on total assets, $S F R_{i t}$ stands for the ratio of stockholders' funds on total assets, and $P C L_{i t}$ is period of creditors' loan. Symbols $\alpha_{i t}$ and $\varepsilon$ are a constant and residuals of panel regression. According to Akinci et al. (2013) we employ the first lags of all exogenous. They argue that that applying a pseudo general-to-specific model reduction method in the application of the GMM estimator avoids multicollinearity problems. Because of the usage of GMM specification it is able to include lagged endogenous $L 2_{i(t-1)}$ among the exogenous regressors.

\section{The model's justification}

Each model should be based on some existing theoretical assumptions according to its justification. Main model in current paper is not an exception.

Whether it is discussed liquidity of any company it is natural that earnings of the company will have a direct impact on its liquidity. Nevertheless, companies in financial loss cannot be liquid. Possible earnings of companies differentiate according to their size. Therefore the return on assets $\left(R O A_{i t}\right)$ is appropriate exogenous variable in the model according equation (6). Moreover, $R O A_{i t}$ is examined as a ratio of EBIT on company's total assets. The problematic of different taxes as well as interest rates among selected countries is irrelevant. On the other hand, it is also possible to use Return on Equity whether it would be examined with EBIT as well. This is not common however. We can assume a positive relationship between $R O A_{i t}$ and liquidity.

Next question is, how can $R O A_{\text {it }}$ increase the liquidity of a company. Liquidity is examined as $L 2_{i t}$, the quick test, when inventories have been excluded. Variable $L 2_{i t}$ is simply calculated as a ratio of current assets (excluding the inventories and long term receivables) on current payables. When the earnings won't be divided among owners of the company, it means that stockholders' funds will increase within the liabilities and simultaneously increase of current receivables (included within $\left.L 2_{i t}\right)$. However, the possible amount of the earnings that can increase the stockholders' funds depends again on a size of company. Therefore the ratio of stockholders' funds $\left(S F R_{i t}\right)$ on total assets is appropriate exogenous variable within the equation (6). Further, during times affected by the global financial crisis, the earnings, whether there were any, should have been reinvested back to a company. We can assume a positive relation between $S F R_{i t}$ and $L 2_{i+1}$ as well.

Nonetheless, when the impact of $R O A_{i t}$ will differentiate from the impact of $S F R_{i t}$, it means that less profitable companies are trying to increase their own funding to increase their liquidity. Higher liquidity means tightening of costs according to a better scoring and lower interest rates on bank loans. Which is a case of negative $R O A_{i t}$ coefficient and positive coefficient for $S F R_{i t}$. Further, positive beta for $R O A_{i t}$ and simultaneously negative beta for $S F R_{i t}$ simply means that earnings are divided among the owners of companies. Both coefficients would be either negative, whether $L 2_{i t}$ can possibly decrease according to a cash transformation into the investments to increase revenues of a company. Which is a case of negative $R O A_{i t}$ as well as negative $S F R_{\text {it }}$ coefficient.

Whether increasing of $L 2_{i t}$ is not supported by significant increasing of $R O A_{i t}$ and simultaneously of $S F R_{i t}$, or at least by significant increasing of $S F R_{i t}$, it means that there is a necessity of other money. Then beta for period of creditors' loan $\left(P C L_{i t}\right)$ should be positive in this case. It means that whereas companies are able to decrease a period in which they have a cash from the receivables, they are simultaneously able to maximize a period in which they should pay the cash for their payables. Such increasing of $P C L_{i t}$ can help increase of the cash among companies and therefore support increasing of $L 2_{i t}$

Furthermore, the values of current as well as of previous period could affect the liquidity. Therefore the usage of GMM model with panel data seems to be efficient for the investigation. According to GMM it is possible to use all the lagged variables, $R O A_{i t t}, S F R_{i(t-1)}, P C L_{i(t-1)}$, even $L 2_{i(t-1)}$.

\section{RESULTS}

Sagan (1955) argued while the money manager's operations are primarily in the area of cash flows, he must be familiar with what is being done with the control of inventories, receivables, and payables. Each of these accounts should soon affect his company's cash position. Excessive inventories can drain funds needed for other purposes or

II: Median among individual samples for HOTELS

\begin{tabular}{|c|c|c|c|c|c|}
\hline & & $L 2_{i t}$ & $R O A_{i t}$ & $S F R_{i t}$ & $P C L_{i t}$ \\
\hline Large & $\mathrm{CZ}$ & 0.89 & 0.00 & 23.78 & 20.38 \\
\hline & PL & 0.80 & 1.96 & 40.50 & 24.99 \\
\hline \multirow{2}{*}{ Medium } & BG & 1.01 & 1.47 & 37.05 & 12.17 \\
\hline & PL & 0.70 & 0.81 & 41.83 & 25.05 \\
\hline
\end{tabular}

Source: Author's calculation. 
might require borrowings. On the other hand, an interruption of production because of inventory shortages might be more costly than the extra inventories. Therefore the inventories have been excluded from the investigation.

In Tab. II we see median values for hotels in Bulgaria (BG), Czechia (CZ), and Poland (PL). Whereas $L 2_{i t}$ is at a lower and similar level within large hotels, we see higher level in BG within those medium sized. In the case of $R O A_{i t}$ we see the highest level within large PL hotels, while the highest one within those medium sized is confirmed in BG again. The zero median is confirmed in both $R O A_{i t}$ medians, CZ large as well as CZ medium sized hotels. However, it should be highlighted that it is obtained even samples with negative values due to losses of the hotels. The medians of $S F R_{i t}$ among those large as well as those medium sized hotels are at a similar level approximately $40 \%$, when it has been excluded those CZ hotels where the median is approximately $20 \%$. The longest period for $P C L_{i t}$ is obvious in PL hotels in both cases.

In Tab. III we see median values for travel agencies in Bulgaria (BG), Czechia (CZ), and Poland (PL). The highest median of $L 2_{i t}$ is confirmed in $B G$ within both cases, large as well as medium sized agencies. The lowest median of $L 2_{i t}$ is confirmed in $\mathrm{CZ}$ within both cases. Whereas in CZ and PL within both cases we see similar median of $R O A_{i t}$, we see much higher in BG within both cases, especially
$R O A_{i t}$ median of large agencies. The highest median of $S F R_{i t}$ is confirmed in BG within both cases of agencies. The lowest median of is confirmed in CZ within both cases. Furthermore, the highest median of $P C L_{i t}$ is confirmed in PL within both cases of agencies. The lowest median of $P C L_{i t}$ is confirmed in CZ within both cases, especially $P C L_{i t}$ median of those medium sized.

Tab. IV contains the estimation output of GMM models with panel data for large as well as medium sized hotels. It was employed two-step GMM model with orthogonal deviations. Even though all examined variables has been accepted as stationary, it was necessary to test Sargan-Hansen (S-H) test according to a possible problem with orthogonality among models. As we see in Tab. IV from the point of view for over-identifying restrictions we accept the null hypothesis which is that the instruments among our models are valid instruments, i.e. uncorrelated with the error term, and that the excluded instruments are correctly excluded from the estimated equations in all cases. Because of usage of orthogonal deviations (no first differences) and further applying a pseudo general-to-specific model reduction method as in Akinci et al. (2013) we can reject any problems with multicollinearity between exogenous variables.

From the results in Tab. IV it is obvious that lagged $L 2_{i(t-1)}$ has positively affected current liquidity $L 2_{i t}$ of hotels among selected countries almost in all cases.

III: Median among individual samples for TRAVEL AGENCIES

\begin{tabular}{lccccc}
\hline & & $L 2_{i t}$ & ROA $_{i t}$ & SFR $_{i t}$ & PCL $_{i t}$ \\
\hline \multirow{2}{*}{ Large } & BG & 1.86 & 18.25 & 46.58 & 12.56 \\
& $\mathrm{CZ}$ & 1.15 & 6.14 & 21.97 & 9.93 \\
\multirow{3}{*}{ Medium } & PL & 1.36 & 7.79 & 39.11 & 16.01 \\
& BG & 1.44 & 10.33 & 40.90 & 11.90 \\
\hline
\end{tabular}

Source: Author's calculation.

IV: Panel GMM estimation output for HOTELS (dependent variable liquidity)

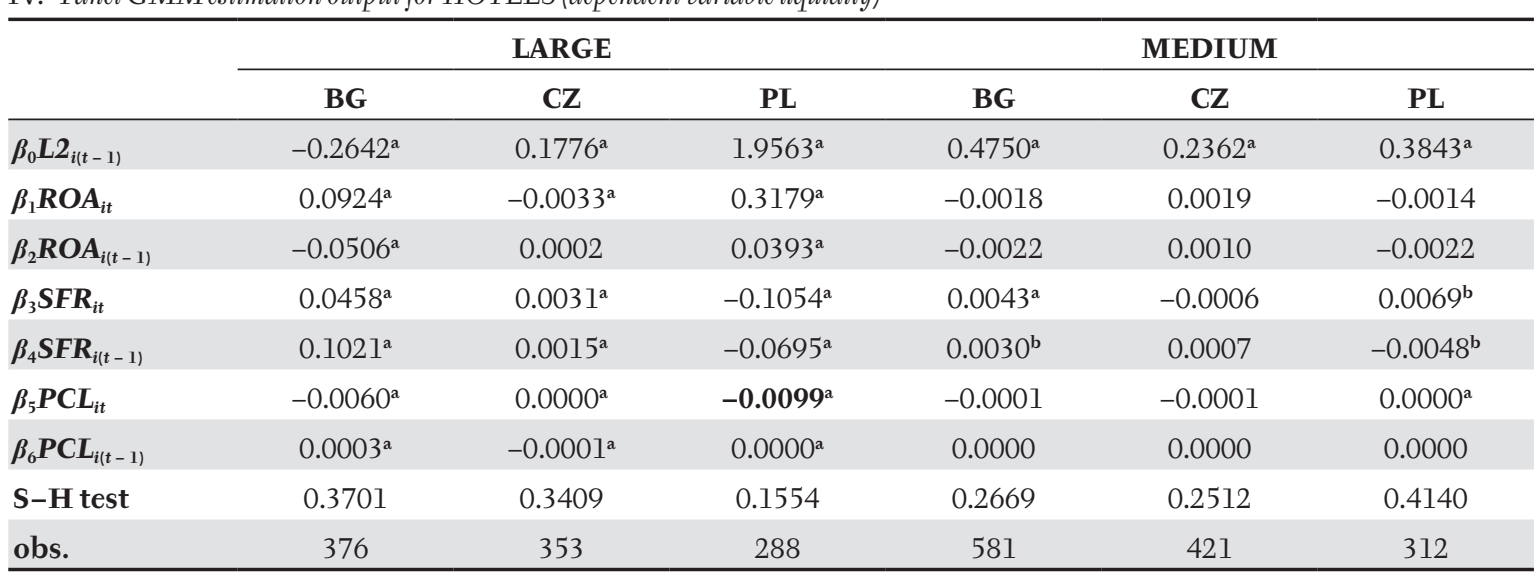

Note: Symbol ${ }^{\mathbf{a}}$ or $^{\mathbf{b}}$ means statistical significance at $1 \%$ or $5 \%$ level.

Source: Author's calculation. 
Only one negative $\beta_{0}$ has been reached within large BG hotels. On the other hand, the biggest influence is evident within large PL hotels. Significant results for $R O A_{i t}$ have been estimated just in the case for large hotels, however, we see differences in negative $\beta_{1}$ within large $\mathrm{CZ}$ hotels. It means that decreasing $R O A_{i t}$ is statistically significant while $L 2_{i t}$ increase among large CZ hotels. Further, large PL hotels would be in much better financial condition whether they are able increase their profitability, which is supported even with positive $\beta_{2}$ for lagged $R O A_{i(t-1)}$. In the case of large BG hotels we see on the other hand negative $\beta_{2} R O A_{i(t-1)}$. Whether it is evident negative significant result for $\beta_{0} L 2_{i(t-1)}$, positive significant result for $\beta_{1} R O A_{i t}$, while $\beta_{2} R O A_{i(t-1)}$ is negative again, we can conclude that $L 2_{i t}$ as well as $R O A_{i t}$ had changed over the estimated period among large BG hotels.

Which should be highlighted from the results in Tab. IV, among large as well as medium sized hotels has been reached positive $\beta_{3} S F R_{i t}$ almost in all cases. Its biggest positive impact is evident among large BG hotels. Just in one case within large PL hotels has been reached negative value of $\beta_{3}$. Whereas large BG hotels have been increased $S F R_{i t}$ while their $L 2_{i t}$ increased, the large PL hotels have oppositely decreased $S F R_{i t}$ while their $L 2_{i t}$ increased. Finally, just in two cases within large BG and large PL hotels is evident negative relationship of smaller $\beta_{5} P C L_{\text {it }}$ according to that should have been increased hotels' liquidity $L 2_{i t}$.

Nevertheless, $S F R_{i t}$ can e.g. positively change according two reasons: (i) increasing of stockholders' funds, or (ii) decreasing of total assets. So, the question whether the results has been estimated while total assets increased or decreased in the case of $S F R_{i t}$ as well as $R O A_{i t}$ could still remain. The only way how to solve this problem, already described above, is whether the sign has differentiated between $R O A_{i t}$ and $S F R_{i t}$, alternatively between $\beta_{2} R O A_{i(t-1)}$ and $\beta_{4} S F R_{i(t-1)}$, from those positive to negative or in opposite way.
Only in this case the difference cannot be caused by the change of total assets. From that point of view we can argue that increase of the stockholders' funds has supported the increasing of $L 2_{\text {it }}$ almost in all cases of those large as well as those medium sized hotels in selected countries. Only one significant result is against the previous predictions within theoretical assumptions of the model. In the case of large PL hotels we see that whereas $R O A_{i t}$ has been increasing, $S F R_{i t}$ has been decreasing. It shows that the earnings among large PL hotels has been divided among their owners. However, even though it has been predicted positive $\beta_{5} P C L_{i t}$ in such a case. We see its negative value, which means that large PL hotels are able even to decrease the $\beta_{5} P C L_{i t}$. Nonetheless, the question, whether it is caused by decreasing of a period in which hotels pay a cash to their creditors or whether it is caused by increasing of a period in which they are able to transform the cash from receivables of their debtors, still remains it this case.

The biggest difference against to Tab. IV is that it has not been reached statistically significant results within large agencies in all countries due to $\mathrm{S}-\mathrm{H}$ test result lower than 0.05 in the case of travel agencies in Tab. V. We have reject orthogonality as well as whole model estimation therefore. Nevertheless, we see the results just in a case of large CZ agencies. Further, the results of this GMM model with panel data is very similar to those results within large CZ hotels in previous Tab. IV. Even though, impact of $\beta_{0} L 2_{i(t-1)}$ is positive, there is negative $\beta_{1}$ for $R O A_{i t}$ again. So, it can be argued that $L 2_{i t}$ is again affected by positive $S F R_{i t}$ within the case of large $\mathrm{CZ}$ agencies, too.

Nonetheless, it has been estimated many significant results within those medium sized travel agencies in Tab. V. The positive impact of lagged $L 2_{i(t-1)}$ remains here except of medium sized PL agencies. What should be highlighted against to the previous case with hotels, in the case with travel agencies is evident opposite trend between $L 2_{i t}$ and $R O A_{i t}$. This trend is followed by increasing of $\beta_{0} S F R_{i t}$. So it can

V: Panel GMM estimation output for TRAVEL AGENCIES (dependent variable liquidity)

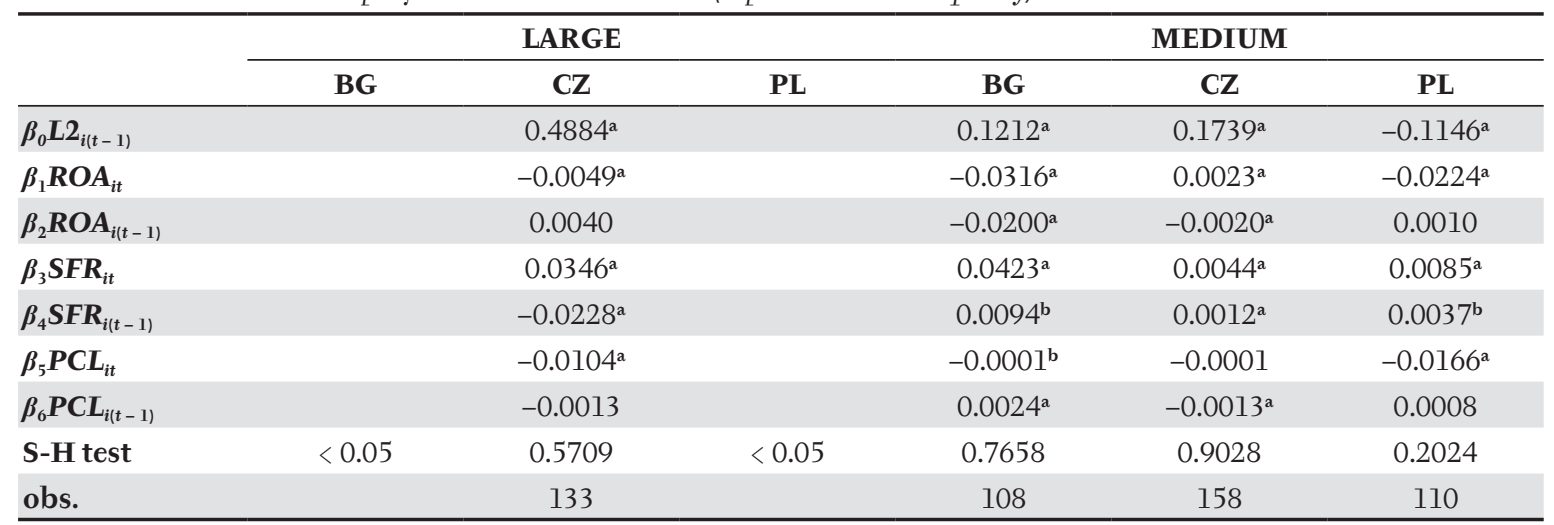

Note: Symbol ${ }^{\mathbf{a}}$ or $^{\mathbf{b}}$ means statistical significance at $1 \%$ or $5 \%$ level.

Source: Author's calculation. 
be really argued that increasing of $S F R_{\text {it }}$ positively affect increasing of $L 2_{i t}$. It is evident that whereas $L 2_{i t}$ has increased $P C L_{i t}$ has decreased oppositely. Again, however, it cannot be said whether the impact of
$P C L_{i t}$ is caused by decreasing of a period in which agencies pay a cash to their creditors or by increasing of a period in which they are able to transform the cash from receivables of their debtors.

\section{DISCUSSION AND CONCLUSION}

Current paper aimed to investigate whether or not was the liquidity among tourism companies in Bulgaria, Czech Republic and Poland affected by other selected microeconomic variables. On the basis of theoretical justification of the model used in this paper, to reach this aim it was selected three financial microeconomic variables. In particular it was return on assets, ratio for stockholders' funds, and the average period of creditors' loan analogically examined from the cash conversion cycle.

Positive impact of previous year's liquidity was obvious among all countries except of large Bulgarian hotels and medium sized Polish travel agencies, where the impact was negative among both. Generally, it was obvious that increasing liquidity was supported by increasing of stockholders' funds during times affected by the global financial crisis. This trend was the strongest in the case of large Bulgarian hotels as well as medium sized Bulgarian travel agencies. Nevertheless, whereas in the case of the hotels the profitability increased, in the case of agencies the profitability decreased in Bulgaria. The same fact as within medium sized Bulgarian travel agencies is obvious within large Czech agencies. Particularly, profitability decreased while stockholders' funds increased among Czech travel agencies. It should be highlighted that companies from the Czech Republic suffered due to exchange rate commitment taken by the Czech National Bank (Heryán, 2017a).

In general, even though profitability of almost all categories of tourism companies was decreasing during the period affected by the global financial crisis, their liquidity was really supported through non-dividing this decreasing profit among company owners. Decreasing profits were reinvested back into the tourism companies to support their liquidity. Otherwise these companies could had been in serious problems with their liquidity in this period. Only one exception was the case of large Polish hotels. The funds among large Polish hotels were decreasing whereas their profitability were increasing. Therefore it is argued that only in this case increasing profits were divided among the hotels owners. Good financial health of the Polish hotels was also highlighted in Heryán (2017b). This fact was also proven because of strongly decreasing period of the period of creditors' loan. Infutureresearchwould beinteresting to make some dummies and testonly those profitable companies as well as those above or below the average liquidity of the sample. From the methodological point of view would be interesting to work with the first differences and employ dummy variables to differ between increasing or decreasing period in which the receivables are transformed into the cash as well as increasing or decreasing period in which payables are paid. Nonetheless, it should be paid a considerable attention to these issues connected to the cash conversion cycle among tourism companies.

\section{Acknowledgements}

This paper was supported by Silesian University in Opava within SGS/7/2018 "Analýza vlivu vybraných aspektů na finanční strukturu podniků v podmínkách zemí střední a východní Evropy".

\section{REFERENCES}

AKINCI, D. A., MATOUSEK, R., RADIĆ, N. and STEWART, C. 2013. Monetary policy and the banking sector in Turkey. Journal of International Financial Markets, Institutions and Money, 27: 269-285.

CAGLE, C. S., CGMA, C. and CAMPBELL, S. N. 1980. Analyzing Liquidity. Management, 9(1): 44-48.

CHANG, C. C. 2018. Cash conversion cycle and corporate performance: Global evidence. International Review of Economics $\sigma$ Finance, 56(C): 568-581.

CREDITREFORM. 2017. Development of insolvencies in Europe. Creditform. [Online]. Available at: https:// www.creditreform.cz/en/press-and-downloads/development-of-insolvencies-in-europe.html [Accessed: 2018, February 22].

DE ALMEIDA, J. R. and EID, W. 2014. Access to finance, working capital management and company value: Evidences from Brazilian companies listed on BM and FBOVESPA. Journal of Business Research, 67(5):924-934.

HERYÁN, T. 2017a. Were the Czech Hotels Able to Confront Current Appreciation of the Czech Currency Before the End of the Exchange Rate Commitment? Acta Universitatis Agriculturae et Silviculturae Mendelianae Brunensis, 65(6): 1925-1933.

HERYÁN, T. 2017b. What influences usage of external financial sources among large and medium sized hotels in V4 countries? In: Proceedings of the 23rd International Scientific Conference on Economic and Social Development. (In print). 
HERYÁN, T. and TZEREMES, P. G. 2017. The bank lending channel of monetary policy in EU countries during the global financial crisis. Economic Modelling, 67: 10-22.

LUO, M. M. 2011. A bright side of financial constraints in cash management. Journal of Corporate Finance, 17(5): 1430-1444.

MOUSSAWI-HAIDAR, L., and JABER, M. Y. 2013. A joint model for cash and inventory management for a retailer under delay in payments. Computers and Industrial Engineering, 66(4): 758-767.

ÖZBAYRAK, M. and AKGÜN, M. 2006. The effects of manufacturing control strategies on the cash conversion cycle in manufacturing systems. International Journal of Production Economics, 103(2): 535-550.

SHERMAN, E. H. 2015. Ratio Analysis for Financial Statements. In: A Manager's Guide to Financial Analysis, Powerful Tools for Analyzing the Numbers and Making the Best Decisions for Your Business. $6^{\text {th }}$ Edition, pp. 39-84.

WANG, Y. J. 2002. Liquidity management, operating performance, and corporate value: evidence from Japan and Taiwan. Journal of Multinational Financial Management, 12(2): 159-169.

ZEIDAN, R. and SHAPIR, O. M. 2017. Cash conversion cycle and value-enhancing operations: Theory and evidence for a free lunch. Journal of Corporate Finance, 45: 203-219. 